\title{
Menyiapkan Protokol Interview, Memilih Informan dan Melakukan Probing dalam Penelitian Kualitatif
}

\author{
Syafrimen Syafril, Nova Erlina Yaumas \\ syafrimen@radenintan.ac.id, novaerlina@radenintan.ac.id \\ Universitas Islam Negeri Raden Intan Lampung, Indonesia
}

\section{Sebelum membuat temubual sebenar, adakah anda melakukan pilot testing?}

Jawapan:

Dalam kajian kualitatif pengkaji adalah sebagai alat utama pengumpul data. Bagaimanapun untuk melakukan temubual pengkaji memerlukan protocol interview sebagai panduan dalam melakukan temubual, supaya temubual yang dijalankan terarah dan tidak keluar daripada permasalahan kajian yang dijalankan. Dari itu, sebelum pengkaji melakukan temubual untuk mengumpulkan data, pembinaan protocol interview pengkaji lakukan terlebih dahulu.

Sebelum protocol interview tersebut digunakan dalam kajian sebenar, pengkaji meminta perkhidmatan beberapa orang pakar untuk menyemak protokol tersebut terlebih dahulu. Sebaik sahaja pengkaji dapat menyusun protokol temubual, pengkaji meminta perkhidmatan beberapa orang pakar untuk menyemak dan memberikan komen terhadap protokol temubual tersebut. Pakar-pakar yang pengkaji maksudkan adalah, pakar dalam bidang psikologi dan kaunseling, serta pakar dalam bidang penyelidikan kualitatif. Setelah pakar berkenaan memberikan pandangan dan komen mereka terhadap protokol yang dibina, pengkaji memperbaiki semula sesuai dengan komen-komen yang mereka berikan.

Bagi memastikan protokol temubual itu dapat digunakan dengan baik dan berkesan dalam pengumpulan data sebenar, pengkaji telah melakukan pilot testing terlebih dahulu kepada beberapa orang subjek, iaitu dengan cara melakukan temubual kepada mereka menggunakan protokol yang pengkaji bina. Melalui pilot testing tersebut pengkaji dapat mengenal pasti sama ada soalan-soalan yang dibina dalam protokol tersebut dapat difahami dengan baik oleh subjek ataupun sebaliknya. Daripada pilot testing yang dijalankan, pengkaji melihat bahawa sememangnya subjek menghadapi kesukaran untuk memahami beberapa soalan yang diberikan kepada mereka, maka pengkaji melakukan perbincangan semula dengan orang yang lebih memahami (penyelia), selanjutnya mengubah soalan-soalan tersebut menjadi lebih baik dan lebih mudah difahami untuk digunakan dalam interview sebenar.

\section{Memilih Informan?}

Dalam penyelidikan kualitatif istilah yang sering digunakan adalah "social situation" (Burhan Bungin 2013; Creswell 2013; Emzir 2013; Sugiyono 2013). Keadaan sosial ini merujuk pada tempat (place), pelaku (actors) dan aktiviti (activity) yang berinteraksi secara bersinergi. Keadaan sosial di sini merujuk kepada situasi sekolah, aktornya adalah pelajar, guru, kaunselor, dan aktivitinya adalah pendidikan ataupun proses kaunseling.

Pemilihan subjek dilakukan mengunakan pendekatan "porposive sampling" iaitu teknik pengambilan subjek dengan pertimbangan tertentu. Pertimbangan dimaksudkan adalah subjek yang dipilih dapat memberikan data sepenuhnya tentang kajian yang pengkaji jalankan. 
Penentuan kriteria subjek tersebut dilakukan oleh pengkaji. Hal ini sesuai dengan pandangan Flick yang menyatakan bahawa pemilihan subjek dalam kajian kualitatif dilakukan mengikut kesesuaian antara permasalahan yang hendak dijawab dalam sesebuah kajian dengan subjek yang akan memberikan data berkaitan dengan permasalahan dalam kajian tersebut.

Untuk jumlah subjek yang akan dilibatkan dalam kajian, Lincoln \& Guba menyatakan "naturalistic sampling is, then, very difference from conventional sampling. It is base on informational, not statistical, consideration. Its purpose is to maximize information, not to facilitate generalization. Pemilihan subjek dalam kajian kualitatif tidak berasaskan pada jumlah ataupun kuantiti sampel seperti dalam kajian kuantitatif, yang penting adalah subjek yang dipilih dapat memberikan maklumat secara maksimum untuk menjawab permasalahan yang dikaji, dan subjek tersebut dapat memberikan maklumat yang lebih kurang sama (sampai pada tahap tepu) terhadap permasalahan yang dikaji.

Lincoln dan Guba juga menyatakan "If the purpose is to maximize information, then sampling is terminated when no new information is fourth-coming from newly sampled units; thus redundancy is the primary criterion" (Sugiyono 2013). Penentuan jumlah subjek dianggap telah memadai apabila data yang didapatkan telah sampai pada tahap "redundancy" ataupun telah sampai pada tahap tepu. Dengan perkataan lain walaupun pengkaji menambahkan subjek baharu namun tidak lagi memberikan maklumat tambahan tentang masalah yang dikaji.

Bungin (2013) menawarkan tiga peringkat pemilihan subjek yang akan dilibatkan dalam kajian, iaitu; (i) pemilihan subjek awal mestilah berkaitan dengan fokus kajian, (ii) pemilihan subjek berikutnya harus dapat memberikan kepelbagain maklumat untuk mengukuhkan data-data yang telah didapatkan sebelumnya, dan (iii) menghentikan pengambilan subjek apabila tidak ditemui lagi maklumat baharu tentang masalah yang dikaji. Bagaimana pun, Bungin menyatakan pemilihan subjek awal menjadi prioriti utama untuk mendapatkan maklumat yang bersesuaian dengan kajian yang dijalankan. Ini penting kerana dapat mempengaruhi kelancaran pengumpulan maklumat penting berikutnya.

Dengan demikian jumlah bilangan subjek tidak menjadi kriteria dalam kajian kualitatif (Johnson 2002). Namun begitu subjek yang dilibatkan dapat menerangkan berbagai perkara berkaitan dengan permasalahan yang dikaji. Untuk tujuan kajian ini pengkaji memerlukan pengalaman pakar untuk pembinaan kemahiran asas menjalankan sesi kaunseling dalam kalangan calon guru kaunseling. Pengalaman yang dikongsikan oleh pakar tersebut sangat penting maknanya untuk mendapatkan gambaran berkaitan dengan bagaimana kemahiran asas kaunseling dalam kaunselor berkenaan dibina. Berapa orang jumlah subjek yang akan dilibatkan belum dapat pengkaji tentutan saat ini, bergantung nantinya pada ketepuan data semasa pengumpulan data dilakukan.

\section{Cara Melakukan Probing:}

Cara melakukan probing atau penggalian data dalam temu bual mmerlukan keterampilan tersendiri dari pengkaji. Sekiranya pengkaji tidak memiliki keterampilan tersebut probing, boleh sahaja pengkaji tidak mendapatkan data yang kaya dengan maklumat untuk kajian yang sedang dijalankan. Bagi kajian-kajian kualitatif yang pernah saya lakukan, biasanya saya 
coba melakukan probing dengan cara merancang soalan protokol dengan baik. Soalan protokol dibuat dalam bentuk pertanyaan terbuka (open question), iaitu subjek bebas menyatakan pandangan mereka berasaskan pertanyaan-pertanyaan yang diberikan kepadanya. Bagaimanapun, pengkaji tetap sahaja memandu temubual tersebut supaya tidak meluas kepada perkara-perkara yang tidak berkaitan dengan kajian yang dijalankan. Untuk melancarkan temubual tersebut, pengkaji menyusun protocol interview tersebut dalam bentuk pertanyaan pembuka, pengenalan, transisi, pertanyaan kunci dan penutup.

Pada pertanyaan pembuka pengkaji memperkenalkan diri sendiri dan juga memberikan ruang kepada subjek untuk memperkenalkan nama dan latarbelakang diri, pengalaman dan sebagainya. Ini sangat penting untuk membuat repo yang baik diantara pengkaji dengan subjek, agar temubual dapat berjalan dengan baik dan lancar. Soalan ini juga sebenarnya bertujuan untuk "ice-breaking" ataupun pembuka tirai perbincangan kepada subjek agar mereka selesa untuk menyampaikan pandangannya dalam perbincangan berikutnya. Melalui pertanyaan pengenalan juga pengkaji coba memperkenalkan secara umum tentang topik temubual dengan subjek. Pertanyaan kunci, merupakan pertanyaan inti yang sangat diperlukan oleh pengkaji untuk mendapatkan jawapan tentang permasalahan yang dikaji. Sedangkan pertanyaan penutup merupakan rumusan daripada temubual yang dijalankan.

Sekiranya pengkaji merancang untuk mengumpulkan data melalui temubual secara individu (indepth interview) dan juga temubual berkumpulan (focus group interview), maka pengkaji menyiapkan protokol untuk masing-masing interviewtersebut. Soalan protokol individu dan soalan protokol berkumpulan dibina lebih kurang sama, hanya terdapat sedikit perbezaan pada soalan pembuka. Soalan pembuka pada soalan protokol temubual individu terus ditujukan kepada individu, sedang soalan pembuka pada temubual berkumpulan cuba menanyakan kepada subjek tentang persamaan dan perbezaan mereka berada dalam kumpulan tersebut.

Melalui temubual secara individu pengkaji mendapatkan maklumat secara mendalam daripada individu yang dilibatkan. Sedangkan melalui temubual berkumpulan pula subjek dapat memberikan pelbagai maklumat kepada pengkaji, untuk melihat kepelbagaian interaksi terhadap perkara yang dibincangkan pada satu masa (Morgan 1997; Krueger 1994). Soalan yang dikemukakan dalam protokol ini berbentuk soalan terbuka dan ianya dijalankan dalam bentuk perbincangan (sama ada temubual individu mahupun temubual berkumpulan). Subjek bebas menyatakan pandangan mereka tentang perkara yang sedang dibincangkan dalam temubual yang sedang dijalankan. Walaubagaimanapun, perjalanan perbincangan tersebut tetap berpandukan kepada soalan protokol yang digunakan(Yin 1994).

Contoh soalan pembuka : Boleh tuan/puan terangkan tentang diri dan pengalaman tuan/puan sepanjang kerjaya tuan/puan, sehingga tuan/puan berada pada tahap sekarang ini?

Soalan pengenalan pula digunakan untuk memperkenalkan topik perbincangan kepada subjek yang terlibat, sama ada dalam temubual individu mahupun berkumpulan. Bahagian ini memberi peluang kepada subjek untuk mengimbas semula pengalaman yang pernah mereka lalui dan diminta mengaitkan pengalaman tersebut dengan topik yang sedang dibincangkan. Soalan ini bertujuan untuk memberikan gambaran kepada subjek tentang isu-isu penting yang menjadi topik perbincangan dalam temubual yang dilaksanakan. Selanjutnya melalui soalan transisi pengkaji cuba memandu subjek kepada topik perbincangan. 
Contoh soalan pengenalan:

Pernahkah tuan/puan mengikuti sebarang kursus ataupun latihan tertentu yang dapat membantu tuan/puan menjalankan tugas dengan baik?

Contoh soalan transisi:

Boleh tuan/puan kongsikan, apakah bentuk-bentuk latihan tersebut? Bagainakah pandangan tuan/puan tentang latihan itu?

Sedangkan soalan kunci pula merupakan soalan-soalan inti untuk mencungkil data daripada subjek yang ditemubual. Melalui soalan-soalan kunci inilah maklumat-maklumat penting diperolehi, yang akan dijadikan sebagai asas data dalam kajian yang dijalankan.

Contoh soalan:

\section{a. Kesedaran Kendiri}

Kesedaran kendiri adalah salah satu domain penting dalam membangunkan EQ seseorang. Kesedaran kendiri ini adalah kemampuan individu untuk: (i) mengetahui perasaan sendiri, (ii) berkeupayaan menilai dengan tepat kekuatan dan kelemahan diri sendiri, (iii) mampu membina keyakinan diri dan (iv) sedar tentang niat dalam diri.

1. Berdasarkan pengalaman tuan/puan adakah elemen-elemen tersebut berperanan dalam mencapai kejayaan sekarang ini?

2. Bagaimana tuan/puan mengaitkanya dengan kejayaan yang telah tuan/puan perolehi sekarang?

3. Apakah yang tuan/puan lakukan untuk membina kesedaran tersebut, sehingga ianya sentiasa wujud dalam diri tuan/puan?

4. Melalui pengalaman tuan/puan, apakah yang telah tuan/puan lakukan untuk mengetahui:

i. Perasaan sendiri

ii. Menilai dengan tepat kekuatan dan kelemahan diri

iii. Membina keyakinan diri

iv. Dan sentiasa sedar tentang niat di dlam diri?

\section{b. Regulasi Kendiri}

Menggambarkan tentang kemampuan seseorang untuk mengawal perasaan yang sedang bergejolak dalam dirinya, sentiasa jujur dalam bertindak, bertanggung jawab dalam melakukan sesuatu, fleksibel dengan perubahan yang berlaku dan mahu menerima idea-idea baru dari sesiapa sahaja tanpa diiringi dengan perasaan negatif.

1. Berdasarkan pengalaman tuan/puan adakah elemen tersebut membantu dalam kejayaan tuan/puan? 
2. Bagaimana tuan/puan mempergunakan elemen-elemen tersebut, sehingga ianya memberikan impak terhadap kejayaan yang tuan/puan dapatkan sekarang ini?

3. Melalui pengalaman yang telah dilalui selama ini, bagaimana tuan/puan memupuk elemen-elemen tersebut, sehingga ianya bersebati di dalam diri tuan/puan?

\section{c. Motivasi Kendiri}

1. Bagaimana tuan/puan memotivasikan diri sendiri untuk mewujudkan kejayaan seperti sekarang ini?

2. Pada pengalaman tuan/puan, bagaimana tuan/puan membina motivasi tersebut sehingga ianya sentiasa menjadi pendorong dalam mewujudkan kejayaan tuan/puan?

3. Apakah yang tuan/puan lakukan untuk memotivasikan diri sehingga berjaya?

\section{d. Empati}

1. Boleh tuan/puan berkongsi pandangan apakah yang tuan/puan faham tentang empati?

2. Mungkin tuan/puan boleh berkongsi pengalaman tentang bagaimana tuan/puan cuba:

(i) Memahami perasaan orang lain?

(ii) Memahami keperluan orang lain?

(iii) Memahami masalah orang lain?

(iv) Dan memahami keperihatinan yang dirasakan oleh orang lain?

3. Kalau tuan/puan melihat ahli keluarga/kakitangan yang mempunyai potensi yang boleh dikembangkan, apakah yang tuan/puan lakukan?

4. Apakah yang tuan/puan lakukan untuk membantu kakitangan tuan/puan sekiranya mereka tidak dapat melihat peluang dalam kerjaya mereka?

\section{e. Kemahiran sosial}

Ialah kemahiran mencetuskan respons yang dikehendaki daripada orang lain. Menggunakan cara yang efektif untuk membujuk orang lain, mampu menerima dan menyampaikan mesej dengan penuh keyakinan dan berkebolehan menyelesaikan konflik dengan baik.

1. Bagaimanakah tuan/puan membina hubungan dengan individu lain? Kenapa Tuan/puan mengatakan begitu?

2. Melalui pengalaman tuan/puan, bagaimakah tuan/puan mempengaruhi orang lain untuk mengikuti cadangan dan idea tuan/puan?

3. Bagaimanakah tuan/puan menyampaikan maklumat kepada orang lain, sehingga orang lain dapat menerima dengan baik?

4. Dalam sesebuah organisasi terkadang berlaku konflik luaran dan dalaman yang mungkin boleh membawa kepada kelemahan sistem sesebuah organisasi, jika tuan/puan berada dalam situasi konflik sedemikian, apakah yang tuan/puan lakukan?

\section{a. Kerohanian}

1. Pada pengalaman tuan/puan selama ini, bagaimana tuan/puan mengaitkan kerja-kerja harian tuan/puan dengan nilai-nilai kerohanian yang tuan/puan yakini? 
2. Bagaimana cara tuan/puan menghayati nilai-nilai kerohanian tersebut, sehingga ianya boleh menjadi pendorong kepada kejayaan yang tuan/puan raih sekarang?

3. Bagaimanakah tuan/puan melaksanakan kerja-kerja harian tuan/puan sehingga ianya dipandang sebagai satu amanah yang mesti dikerjakan dengan penuh keikhlasan?

\section{b. Kematangan}

1. Apakah persamaan dan perbezaan yang tuan/puan rasakan ketika mula-mula menceburkan diri dalam kerjaya, dimana tuan/puan telah lama berada di dalam kerjaya tersebut?

2. Apakah faktor-faktor yang membawa kepada kejayaan dalam diri tuan/puan?

3. Untuk sampai pada peringkat sekarang ini, tentunya tuan/puan mempunyai pelbagai pengalaman, bagaimana agaknya tuan/puan mempergunakan pengalaman tersebut untuk memperbaiki keadaan yang tuan/puan hadapi sekarang?

4. Setelah melalui pelbagai rintangan dalam kerjaya, apakah yang tuan/puan rasakan pada saat ini?

Manakala soalan penutup pula merupakan rumusan daripada perbincangan yang dijalankan. Sekiranya masih terdapat perkara-perkara penting yang perlu dikongsikan oleh subjek tentang topik perbincangan yang tidak tertanya oleh pengkaji, maka pada bahagian penutup ini subjek dapat menyampaikan perkara tersebut. Selepas soalan penutup pengkaji mengucapkan terima kasih atas kesediaan dan masa yang diluangkan oleh subjek. Pengkaji menyatakan kepada subjek, sekiranya hasil temubual ini selesai dibuat dalam bentuk transkripsi, maka pengkaji meminta tolong semak semula hasil transkripsi yang dibuat bagi memastikan data-data yang diberikan sesuai dengan yang dimaksudkan oleh subjek-subjek yang memberikan pandangan.

Contoh soalan: (i) Kita telah berbincang lama, secara umumnya apakah pandangan tuan/puan tentang perkara-perkara yang telah kita bincang tadi? (ii) Adakah perkaraperkara yang tertinggal atau yang ingin tuan/puan tambahkan dalam perbincangan kita tadi?

Inilah diantara contoh yang saya lakukan bagaimana saya melakukan probing untuk menggali data dalam melaksanakan temu bual. Seperti saya kemukakan di atas iaitu salah satunya dengan cara merancang soalan protocol seperti ditunjukkan dia atas.

Menurut saya, sebenarnya probing juga boleh dilakukan dengan cara mendalami data daripada jawapan yang diberikan oleh informan ataupun subjek kajian. Pengkaji dapat menggali sebih dalam lagi maklumat yang disampaikan oleh informan dalam interview yang dilakukan.

Sebagai contoh:

Tadi Tuan/Puan mengatakan bahawa empati itu adalah satu perkara yang sangat penting dimiliki oleh seorang kaunselor, kenapa Tuan/Puan berpandangan begitu?

Boleh Tuan/Puan berikan contoh, seperti apa sebenarnya kepentingan empati itu bagi seorang kaunselor? 
Pengkaji boleh terus menggali secara mendalam semua maklumat yang diperlukan. Menurut saya boleh juga melakukan probing dengan cara seperti itu.

\section{Contoh kepada jenis-jenis soalan berikut:}

4.1 Hypothetical question:

Menurut Tuan/Puan, apakah yang akan berlaku sekiranya seorang kaunselor tidak memiliki sifat empati yang tinggi......?

4.2 Devil advocate question:

4.3 Ideal position question:

(i) Bagaimanakah tuan/puan membina hubungan dengan individu lain? Kenapa Tuan/puan mengatakan begitu?

(ii) Melalui pengalaman tuan/puan, bagaimakah tuan/puan mempengaruhi orang lain untuk mengikuti cadangan dan idea tuan/puan?

(iii)Bagaimanakah tuan/puan menyampaikan maklumat kepada orang lain, sehingga orang lain dapat menerima dengan baik?

4.4 Interpretive question:

Pertanyaan yang menimbulkan interpretasi yang bermacam-macam sehingga informan tidak dapat memberikan respon yang baik terhadap pertanyaan yang diajukan kepada mereka.

Contoh:

Bagaimana menurut tuan/puan isu-isu tentang kaunseling saat ini?

Pertanyaan seperti ini dapat memunculkan berbagai tafsiran, boleh jadi informan menanggapi isu tentang kaunselor, boleh jadi tentang klie, atau isu-isu terkait dengan kaunseling yang lainya. Jadi menimbulkan pelbagai tafsiran. Sepetutnya dalam interview memberikan pertanyaan yang fokus sehingga memperolehi data yang mendalam.

\section{Contoh kepada jenis-jenis penyoalan yang perlu dielakan:}

\subsection{Multiple question:}

Mengajukan pertanyaan yang terlalu banyak dalam satu masa, sehingga informan tidak pasti mahu menjawab yang mana, dengan perkataan lain pertanyaan-pertanyaan seperti ini membuatkan informan jadi stag, sehingga tidak tahu harus menjawab yang mana terlebih dahulu.

Contoh:

Bagaimana tuan/puan mengaitkan antara kejayaan tuan/puan sekarang dengan perjalanan hidup tuan/puan? Apakah yang tuan/puan lakukan untuk itu? Melalui pengalaman tuan/puan, apakah yang telah tuan/puan lakukan untuk mengetahui: i.Perasaan sendiri, ii. Menilai dengan tepat kekuatan dan kelemahan diri, iii. Membina keyakinan diri, iv. Dan sentiasa sedar tentang niat di dlam diri? 
5.2. Leading question:

Pertanyaan yang terlalu dipimpin, informan tidak leluasa dalam memberikan respons mereka.

Contoh:

Empati itu adalah bagaimana seorang kaunselor cuba merasakan apa yang dirasakan oleh klien. Adakah tuan/puan setuju dengan itu?

Seorang kaunselor perlu sekali memiliki sifat empati yang tinggi. Bagaimana tuan/puan, iya atau tidak? 